The Spectrum of

\title{
NREL Creates New Pathways for Producing Biofuels and Acids from Cyanobacteria
}

Cyanobacteria use photosynthesis to convert carbon dioxide into sugars such as glycogen, a carbohydrate that is stored in the cells as an energy source. However, researchers at the National Renewable Energy Laboratory (NREL) have discovered that this photosynthesis can be redirected to produce lipids and valuable organic acids. The research could yield a new source of chemicals and biofuels, because the lipids can potentially be extracted from the bacteria and converted into biodiesel.

Though cyanobacteria are known as blue-green algae, this is actually a misnomer, as they are bacteria rather than algae. In searching for potential sources of lipids, NREL scientists deemed both algae and cyanobacteria preferable to plants. Simply put, normal plants have parts such as stems that don't photosynthesize, meaning they would have a lower lipid yield than more efficient microbes. Algae have limits too, particularly because genetic tools for them have not been fully developed.

Instead, the scientists chose a cyanobacterium, Synechocystis 6803. This strain has a fully sequenced genome, and the genetic tools that allow researchers to change any gene and observe the effect of those changes. Yet cyanobacteria don't really produce much oil, so the challenge was to figure out how to manipulate the oil production via genetics.

In fiscal year 2009, NREL researchers sought to test the hypothesis that cyanobacteria's photosynthesis could be engineered to produce greater quantities of lipids. The project began with a threefold experimental goal: to block glycogen synthesis and evaluate how that affected the flow of carbon within the bacteria; to introduce genes to enable the production

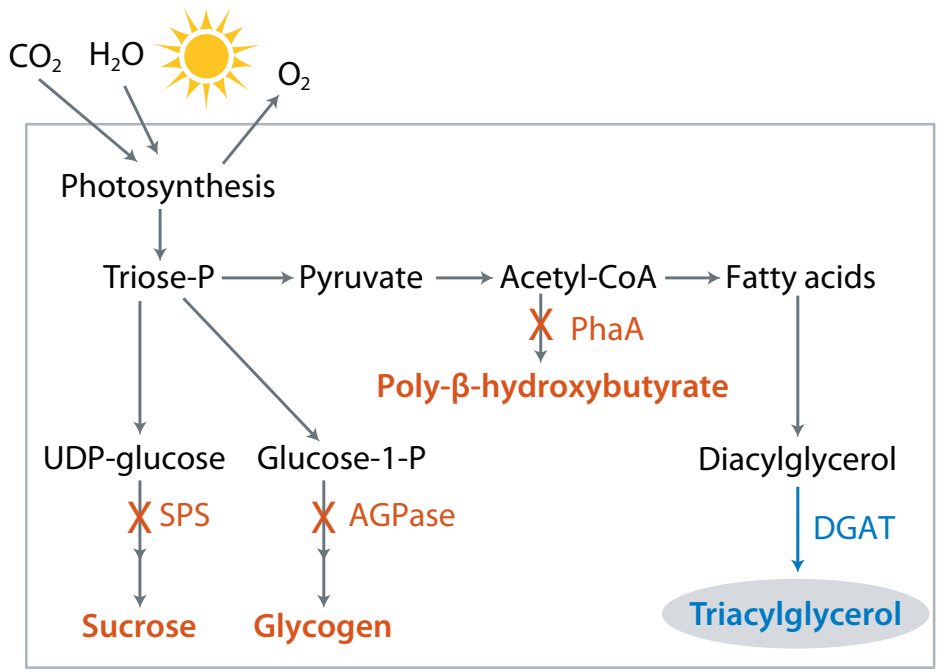

In cyanobacteria, photosynthesis normally proceeds through several pathways to produce sucrose, glycogen, or poly-ßhydroxybutyrate, as well as other products. NREL researchers blocked those pathways and introduced a gene to produce the enzyme diacylglycerol acyltransferase (DGAT), yielding a new pathway for the production of triacylglycerol, which can be used to produce biodiesel. Illustration by Stacy Buchanan
Clean Energy Innovation

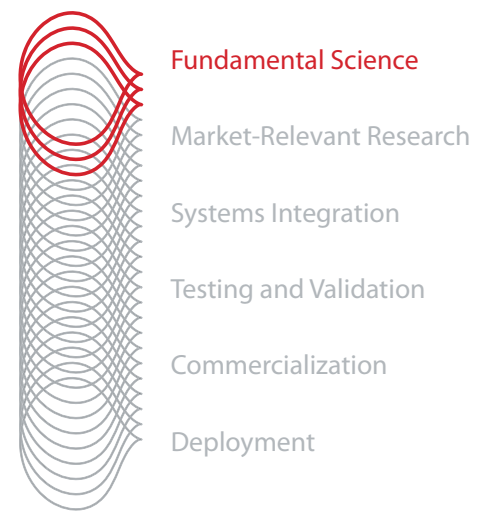

Through deep technical expertise and an unmatched breadth of capabilities, NREL leads an integrated approach across the spectrum of renewable energy innovation. From scientific discovery to accelerating market deployment, NREL works in partnership with private industry to drive the transformation of our nation's energy systems.

This case study illustrates NREL's innovations in Fundamental Science

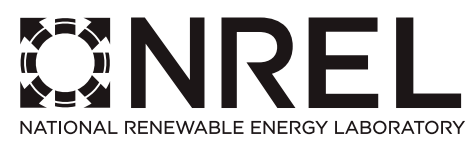

NREL is a national laboratory of the U.S. Department of Energy, Office of Energy Efficiency and Renewable Energy, operated by the Alliance for Sustainable Energy, LLC. 
of triacylglycerol (TAG), a biodiesel precursor; and to use physiological manipulations to improve the TAG yields. Cyanobacteria, including the genetic model Synechocystis 6803, produce glycogen through the glucose 1-P pathway (see the front-page illustration), which the NREL researchers opted to mutate by inactivating the gene that makes the AGPase enzyme.

\section{Creating a New Oil Synthesis Pathway}

The team then began to look at Synechocystis' genes and lipids in order to figure out its natural lipid synthesis pathways. It occurred to the researchers that the addition of one enzyme, diacylglycerol acyltransferase (DGAT), would allow the bacteria to produce TAG.

The group employed a well-characterized gene coding for the enzyme DGAT. They created a new version of the gene tailored for Synechocystis, then transferred the gene into the organism. They then looked for the presence of DGAT in the mutant strain.

By 2011, the NREL research team was able to complete DNA and protein testing to confirm that DGAT was present in the NREL-created mutant. They then confirmed that it was working as predicted, producing TAG, unlike the wild type of the cyanobacteria that doesn't have any TAG synthesis pathway.

However, the team found that only a low level of TAG was being produced, comprising less than $1 \%$ of the cell biomass. Although this was far from being economical in terms of biofuel production, the researchers had succeeded by establishing a starting point for the production of biodiesel from cyanobacteria.

\section{An Unexpected Twist in the Findings}

As the experiment unfolded, the NREL researchers discovered something more: under conditions when glycogen normally accumulates, the glycogen synthesis mutant cells became catalysts and created a large quantity of organic acids from carbon dioxide.

Because the researchers had blocked the normal pathway for glycogen synthesis in the mutant, it no longer made glycogen. Still, the NREL scientists saw that the Synechocystis was engaging in photosynthesis and knew the organism was still taking carbon from the atmosphere.

Through additional testing, the researchers learned that the cells were releasing the carbon outside the cells in the form of two organic acids: alpha ketoglutarate (AKG) and pyruvate. It was evident that the cells were no longer growing, but doing work in the catalytic mode.

One theory for the organic acid production was that the cells were trying to get rid of excess energy that they could not use or store, so they produced large quantities of organic acids instead. The researchers had, in effect, engineered a new biological avenue for producing organic acids at a large scale from sunlight and carbon dioxide.

This could prove to be a significant finding, because the organic acids could be converted into chemicals and fuels. As a result of this pioneering work, the group has filed a U.S. patent application for this process.

In future work, the NREL researchers will continue using their findings to further the technology. The genetic model will aid their understanding of molecular regulation of the carbon metabolism in photosynthetic organisms, including algae. The outcome can guide the design and development of recombinant green algal strains for biofuel synthesis, in addition to the potential large-scale production of biofuels and chemicals using the mutant cyanobacteria.

\section{Cyanobacteria and the Ethylene Economy}

Cyanobacteria are proving to be workhorses for the biobased production of chemicals, producing more than just biofuels and organic acids. In 2010, NREL researchers used the cyanobacterium Synechocystis 6803 to establish that carbon dioxide and water can be continuously converted to ethylene, the most widely produced petrochemical feedstock.

Currently, ethylene is produced from fossil fuels in a process called "steam cracking," which is the largest carbon dioxide emitter in the chemical industry. Developing a sustainable, carbon-neutral process to produce this chemical is essential. Because fossil fuels were formed by plants and algae that grew millions of years ago, researchers have asked whether we could bypass the fossil fuels and tap live organisms to produce ethylene.

The NREL team answered that question by creating genetically engineered strains of cyanobacteria that produce ethylene continuously, and at rates surpassing the previous record for producing chemicals from sunlight. Now researchers are focusing on how to make the process economical, so the tiny single-celled organism can actually produce ethylene on a large scale.

This could help achieve the U.S. Department of Energy's goal of replacing the whole barrel of oil with biobased equivalents. Simply replacing fuels like gasoline with biofuels is not enough, because oil is converted into a wide range of petrochemicals that are essential for the chemical industry.

Ethylene is used to produce a wide variety of materials, including plastics, textiles, and antifreeze. In addition, ethylene can be polymerized into fuels such as gasoline, diesel fuel, and jet fuel, using a process known for the past 70 years.

\section{National Renewable Energy Laboratory}

15013 Denver West Parkway

Golden, CO 80401

303-275-3000 • www.nrel.gov

NREL is a national laboratory of the U.S. Department of Energy, Office of Energy Efficiency and Renewable Energy, operated by the Alliance for Sustainable Energy, LLC.

NREL/FS-6A42-55974 • October 2012

Printed with a renewable-source ink on paper containing at least $50 \%$ wastepaper, including $10 \%$ post consumer waste.

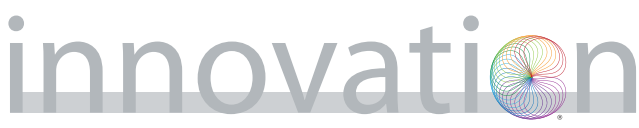

